\title{
Comparison of fibre optical measurements and discrete element simulations for the study of granulation in a spout fluidized bed
}

\author{
J.M. Link ${ }^{1}$, W. Godlieb ${ }^{1}$, P. Tripp ${ }^{2}$, N.G. Deen ${ }^{1, *}$, S. Heinrich ${ }^{3}$, M. Peglow ${ }^{3}$, J. Kumar ${ }^{3}$, \\ J.A.M. Kuipers ${ }^{1}$, M. Schönherr ${ }^{4}$ and L. Mörl ${ }^{3}$ \\ 1: University of Twente, P.O. Box 217, 7500 AE Enschede, The Netherlands. \\ 2: University of Applied Sciences Frankfurt, 60318 Frankfurt, Germany \\ 3: Otto-von-Guericke-University Magdeburg, 39106 Magdeburg, Germany \\ 4: BASF Aktiengesellschaft, 67056 Ludwigshafen, Germany \\ *Corresponding author, E-mail: N.G.Deen@utwente.nl, \\ Tel: +31-53-489 4138, Fax: +31-53-489 2882
}

\begin{abstract}
Spout fluidized beds are frequently used for the production of granules or particles through granulation. The products find application in a large variety of applications, for example detergents, fertilizers, pharmaceuticals and food. Spout fluidized beds have a number of advantageous properties, such as a high mobility of the particles, which prevents undesired agglomeration and yields excellent heat transfer properties.

The particle growth mechanism in a spout fluidized bed as function of particle-droplet interaction has a profound influence on the particle morphology and thus on the product quality. Nevertheless, little is known about the details of the granulation process. This is mainly due to the fact that the granulation process is not visually accessible. In this work we use fundamental, deterministic models to enable the detailed investigation of granulation behaviour in a spout fluidized bed.

A discrete element model is used describing the dynamics of the continuous gas-phase and the discrete droplets and particles. For each element momentum balances are solved. The momentum transfer among each of the three phases is described in detail at the level of individual elements.

The results from the discrete element model simulations are compared with local measurements of particle volume fractions as well as particle velocities by using a novel fibre optical probe in a fluidized bed of $400 \mathrm{~mm}$ I.D. Simulations and experiments were carried out for two different cases using Geldart B type aluminium oxide particles: a freely bubbling fluidized bed and a spout fluidized bed with the presence of droplets. It is demonstrated how the discrete element model can be used to obtain information about the interaction of the discrete phases, i.e. the growth zone in a spout fluidized bed. Eventually this kind of information can be used to obtain closure information required in more coarse grained models.
\end{abstract}

KEYWORDS: Spout fluid bed, Granulation, Discrete element model, Fibre optical measurement

\section{INTRODUCTION}

In the chemical and pharmaceutical industry granular products are agglomerated, granulated or coated to enhance their handling properties, e.g. instant properties, controlled release or protection for chemical reactions. Fluidized beds are widely used for agglomeration, granulation and coating tasks because of their excellent heat and mass transfer and mixing properties. The liquid binding or coating material (suspension, solution or melt) is usually injected into the fluidized bed via a nozzle. The injection into the fluidized bed can be realized as bottom spray, top spray or horizontal spray. Because of their good atomization properties pneumatic two-fluid nozzles are the preferred nozzles. The process conditions in the injection zone have a strong influence on the local particle volume concentrations, particle velocities, deposition of the liquid droplets and the solidification of the solid content of the liquid and the subsequent product quality. That is why the understanding of the mechanism 
occurring in the injection zone is essential in order to achieve and control desired product qualities. But in spite of the common use of fluidized beds for agglomeration, granulation and coating tasks only a few investigations on the injection into fluidized beds are available in the open literature.

Contributions to this research have been reported by Merry [1,2], Massimilla et al. [3-9], Yang et al. [10,11] and Hong et al. [12].

Merry [2] and Yang et al. [10,11] investigated the jet penetration depth in fluidized beds and proposed different correlations for the calculation of the jet penetration depth. In an experimental study Merry [1] investigated the movement of the fluid and particles in the neighbourhood of a jet in a solid-liquid fluidized bed. Based on these investigations Merry developed a sink and source model for the calculation of the solids entrainment rate into a jet in a fluidized bed. Massimilla et al. [3-9] did a lot of experimental investigations on gas jets in fluidized beds. In these investigations they studied the momentum dissipation of the jet in the fluidized bed by measuring the gas velocity profiles in the jet region with a pitot tube. They developed a model based on the theory of turbulent free jets. The local gas and particle velocities and the particle volume concentrations in the jet can be calculated with this model. The model shows good agreement with the experimental results. Becher et al. [13,14] present a model also based on the theory of a free jet which allows the calculation of the gas-solid flow and moisture distribution in the spray zone of a two-fluid nozzle in a fluidized bed. The model parameters were adjusted to experimental measurements of the average circulation time of a tracer particle in a fluidized bed. Hong et al. [12] proposed a two-fluid Eulerian model for a gas jet in a fluidized bed. In order to verify their model they calculated the jet penetration depth and compared these calculated jet penetration depths with experimental data and different correlations for the jet penetration depth proposed in the literature. Heinrich et al. $[15,16]$ present a new multidimensional model for the calculation of local gas and solid temperatures in top sprayed fluidized bed granulators. The solid dispersion in the fluidized bed is described by dispersion coefficients. The deposition of the injected liquid on the fluidized particles is described by a model, that calculates the atomization process and the deposition of droplets on the particles. Recently Kuipers et al. [17] reported their work on gas-solid fluidized beds with a jet. In the work a critical comparison between two closure models for an Eulerian approach was reported. The first closure model is a semi-empirical model assuming constant viscosity of the solid phase and the second model is based on the kinetic theory of granular flow. The numerical simulations show, that the kinetic theory of granular flow and semi-empirical model of a constant viscosity of the solid phase give very similar predictions. Link et al. [18] used an Euler-Lagrange model to describe the gas-particle flow in a spout fluid bed. They verified both the numerical implementation as well as the closure model for the gas-particle drag force. They found that the model is able to quantitatively predict several flow regimes in a spout fluid bed provided that the interfacial coupling is treated properly.

As the overview over the literature demonstrates there is still a lack of experimental and theoretical work to enhance the mechanism occurring during the injection of liquids in fluidized beds used for agglomeration, granulation or coating tasks.

In this paper first results of a detailed experimental and numerical investigation on local particle volume concentrations, particle velocities in the jet region of a two-fluid nozzle in a fluidized bed and the size of the spraying zone in a fluidized bed are presented.

\section{EXPERIMENTAL TECHNIQUE}

The experimental investigations described in this paper were carried out in a cylindrical fluidized bed in pilot-plant scale with a diameter of $400 \mathrm{~mm}$, depicted in Figure 1. The fluidized bed was operated as a bottom sprayed fluidized bed. A pneumatic-two-fluid nozzle (Lechler , nozzle type 721.001.17.31) was used for the injection of either only gas or gas and water into the fluidized bed. This nozzle is an externally-mixing nozzle. The gas escaping at high speed, in a rotating motion, from a ring gap atomizes the liquid discharged at a significantly lower velocity from the center of the nozzle. The diameter of central pipe is 1.3 $\mathrm{mm}$ and the outer diameter of the ring gap is $11 \mathrm{~mm}$. 

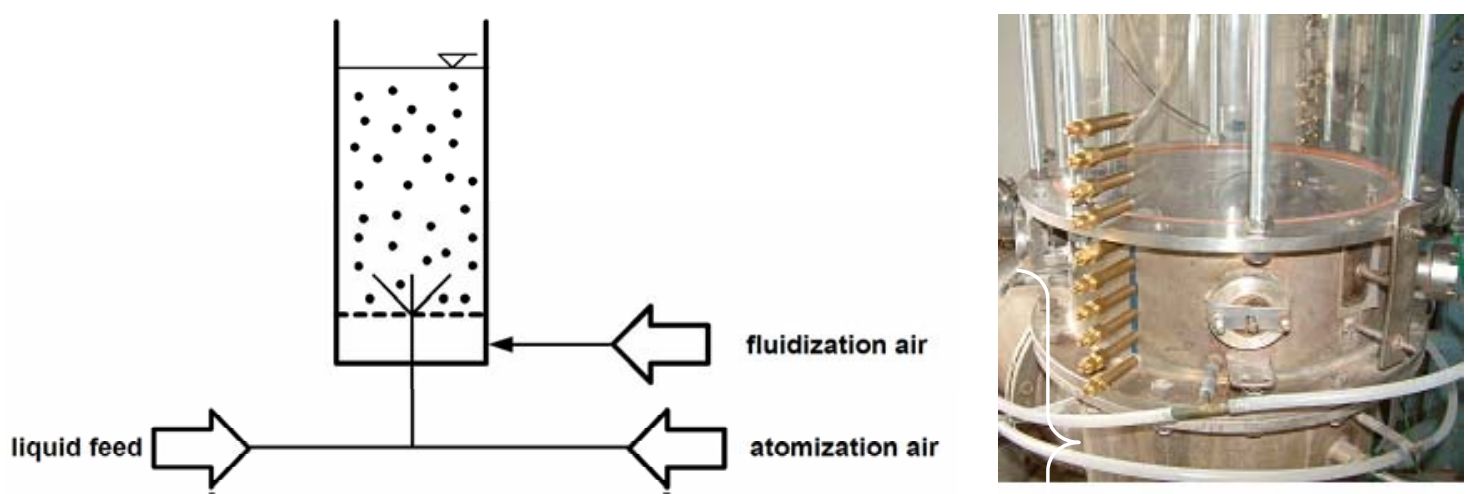

Figure 1 Flow sheet of the fluidized bed (left) and close-up of the bottom section of the fluidized bed, showing the positions of the measurement probes (right).

Porous monodisperse $\gamma-\mathrm{Al}_{2} \mathrm{O}_{3}$ particles with a diameter of $1.8 \mathrm{~mm}$ were used as fluidized bed material. This ceramic material $\left(C_{p}=940 \mathrm{~kJ} /(\mathrm{kg} \mathrm{K}), \lambda_{p}=0.24 \mathrm{~W} /(\mathrm{m} \mathrm{K})\right)$ is often used as catalyst carrier and adsorbing agent in chemical industry. Because of the spherical structure of the particle, its big inner surface and with its highly water-absorbing capacity $\gamma-\mathrm{Al}_{2} \mathrm{O}_{3}$ is very appropriate as model substance. The granular density of the particles was measured with a helium-pycnometer and is $1040 \mathrm{~kg} / \mathrm{m}^{3}$ and the solid density is $3230 \mathrm{~kg} / \mathrm{m}^{3}$. The inner surface of the granules is $145 \mathrm{~m}^{2} / \mathrm{g}$ and the porosity of the particles is $69.3 \%$.

The measurements of the porosities and particle velocities in the fluidized bed were carried out with a new fibre optical probe especially designed for this task. The measuring system consists of the probe, a data acquisition system and a laptop. The probe depicted schematically in Figure 2 consists of an array of optical fibres. In the center of the probe there is one row of optical fibres emitting infrared light into the fluidized bed. The light reflected by the particles passing the probe is detected by two rows of optical fibres. The intensity of the light reflected by the particles passing the probe is a quantity for the porosity. The reflected light is transmitted to IR- light detectors which create a corresponding voltage signal. The calibration procedure was carried out in the same way as proposed by Hartge et al. [19].

In order to measure the particle velocities the signals of the two detecting fibre optical rows are measured with two different IR detectors. Thus, it is possible to measure the velocity of a particle moving perpendicular to the detecting fibre optical rows by evaluating the time difference between the two signals and the distance between the two detecting fibre optical rows. The time difference is calculated by a cross correlation of the two signals.

In order to measure the porosity and vertical particle velocity components at different radial positions and different heights from the bottom plate the fibre optical probe can be inserted into the fluidized bed through 10 different probe tubes positioned at the circumference of the fluidized bed.

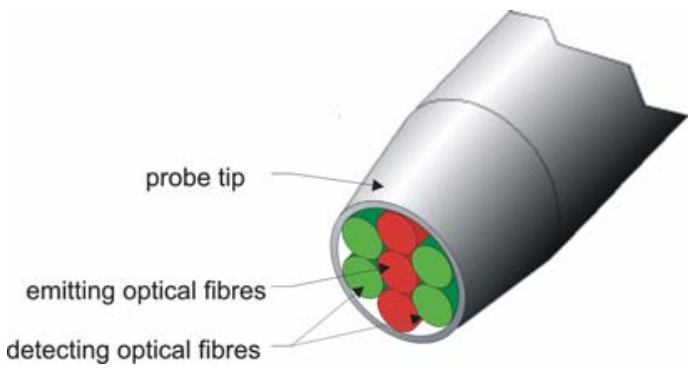

Figure 2 Schematic sketch of the fibre optical probe

\section{NUMERICAL MODEL}

The discrete particle model used in this work is based on the hard-sphere model developed by Hoomans et al. [20] and Link et al. [18]. A short description of the model is given in this section, for details the interested reader is referred to references [20,18].

The motion of every individual element $i$ (particle or droplet) in the system is calculated from Newton's law: 
$m_{i} \frac{d \mathbf{v}_{i}}{d t}=-V_{i} \nabla p+\frac{V_{i} \beta}{\varepsilon_{s}}\left(\mathbf{u}-\mathbf{v}_{i}\right)+m_{i} \mathbf{g}$

where the forces on the right hand side are respectively due to pressure, drag and gravity.

$\beta$ represents the inter-phase momentum transfer coefficient and is modeled through a drag relation that was recently obtained from lattice Boltzmann simulations by Koch and Hill [21]:

$$
\begin{aligned}
& \beta=\frac{18 \mu \varepsilon_{g}^{2} \varepsilon_{s}}{d_{p}^{2}}\left[F_{0}\left(\varepsilon_{s}\right)+0.5 F_{3}\left(\varepsilon_{s}\right) \mathrm{Re}\right] \\
& F_{0}\left(\varepsilon_{s}\right)=\frac{1+3\left(\varepsilon_{s} / 2\right)^{1 / 2}+(135 / 64) \varepsilon_{s} \ln \varepsilon_{s}+17.14 \varepsilon_{s}}{1+0.681 \varepsilon_{s}-8.48 \varepsilon_{s}^{2}+8.16 \varepsilon_{s}^{3}} \\
& F_{3}\left(\varepsilon_{s}\right)=0.0673+0.212 \varepsilon_{s}+\frac{0.0232}{\varepsilon_{g}^{5}}
\end{aligned}
$$

Particle collision dynamics are described by collision laws, which account for energy dissipation due to non-ideal particle interaction by means of the empirical coefficients of normal and tangential restitution and the coefficient of friction.

The particle collision characteristics play an important role in the overall bed behavior as was shown by Hoomans et al. [20] and Goldschmidt et al. [22]. For this reason the collision properties of the particles as determined by Kharaz et al. [23] were used in the simulations.

The gas phase hydrodynamics are calculated in three dimensions from the volume-averaged Navier-Stokes equations:

$$
\begin{aligned}
& \frac{\partial}{\partial t}\left(\varepsilon_{g} \rho_{g}\right)+\nabla \cdot\left(\varepsilon_{g} \rho_{g} \mathbf{u}\right)=0 \\
& \frac{\partial}{\partial t}\left(\varepsilon_{g} \rho_{g} \mathbf{u}\right)+\nabla \cdot\left(\varepsilon_{g} \rho_{g} \mathbf{u} \mathbf{u}\right)=-\varepsilon_{g} \nabla p-\nabla \cdot\left(\varepsilon_{g} \boldsymbol{\tau}\right)-\mathbf{S}_{p}+\varepsilon_{g} \rho_{g} \mathbf{g}
\end{aligned}
$$

The two-way coupling between the gas-phase and the particles is achieved via the sink term $\mathbf{S}_{\boldsymbol{p}}$, which is computed from:

$$
\mathbf{S}_{p}=\frac{1}{V_{\text {cell }}} \int \sum_{i=0}^{N_{p}} \frac{V_{i} \beta}{\varepsilon_{s}}\left(\mathbf{u}-\mathbf{v}_{i}\right) D\left(\mathbf{r}-\mathbf{r}_{i}\right) d V
$$

The distribution function $D$ locally distributes the reaction force acting on the gas phase to the Eulerian grid via appropriate weighing functions (see [18] for more details).

With the use of the DEM the interaction between droplets and particles and the evolution of the particle size distribution as encountered in granulation processes, can be modelled in a deterministic fashion. Two simulations were performed to enable a comparison with the experimental data. In order to reduce the computational time to reasonable limits, two simplifications were made to the system. First of all, the bed was modelled as a square channel, rather than a cylindrical fluidized bed. This assumption is justified, since the influence of the walls is limited, given the large diameter of the bed and the small filling height of the bed. Furthermore, the total number of particles was considerably reduced, while keeping the total particle volume constant. This was accomplished by increasing the particle from $1.8 \mathrm{~mm}$ to $5.4 \mathrm{~mm}$. Finally, the particle density was changed in such way that the minimum fluidization velocity of the particles in the simulations is the same as in the experiments. 


\section{RESULTS}

In this section results of numerical simulations and fibre optical probe measurements are discussed for two different cases. In both cases a spout fluid bed was considered with $\gamma$ alumina particles packed to a static height of $0.3 \mathrm{~m}$. The particles in the bed are fluidized through background fluidization air, which enters the bed throughout the entire bottom. In the first case, this operation mode gives rise to the bubbling bed regime. In the second case, atomization air and liquid are introduced to the bed through a nozzle (i.e. the spout). The liquid leaves the nozzle in the form of droplets, which deposit on the particles. The particles are porous and subsequently absorb the liquid. In the simulations the interaction between the droplets and the gas phase is handled through one-way coupling. That is to say that the droplets are assumed to enter the bed at their terminal velocity and thereafter follow the gas stream. The effect of the droplets on the phase fractions and the feedback effects from the droplets to the gas phase are neglected. The properties of all the phases, along with the numerical settings are presented in Table 1.

Table 1. Physical properties and numerical settings for the simulations and experiments.

\begin{tabular}{|c|c|c|c|c|c|c|}
\hline \multirow[b]{2}{*}{ Parameter } & \multirow[b]{2}{*}{ Symbol } & \multicolumn{2}{|c|}{ Simulations } & \multicolumn{2}{|c|}{ Experiments } & \multirow[b]{2}{*}{ Unit } \\
\hline & & $\begin{array}{l}\text { Without } \\
\text { injection }\end{array}$ & $\begin{array}{c}\text { With } \\
\text { injection }\end{array}$ & $\begin{array}{l}\text { Without } \\
\text { injection }\end{array}$ & $\begin{array}{c}\text { With } \\
\text { injection }\end{array}$ & \\
\hline $\begin{array}{l}\text { Initial particle } \\
\text { diameter }\end{array}$ & $d_{p}$ & 5.4 & 5.4 & 1.8 & 1.8 & $\mathrm{~mm}$ \\
\hline Particle density & $\rho_{p}$ & 248 & 248 & 1040 & 1040 & $\mathrm{~kg} / \mathrm{m}^{3}$ \\
\hline Number of particles & $N_{p}$ & $1.6 \cdot 10^{5}$ & $1.6 \cdot 10^{5}$ & $4.2 \cdot 10^{6}$ & $4.2 \cdot 10^{6}$ & - \\
\hline Droplet diameter & $d_{d}$ & n.a. & 100 & n.a. & 100 & $\mu \mathrm{m}$ \\
\hline Droplet density & $\rho_{d}$ & n.a. & 248 & n.a. & 1000 & $\mathrm{~kg} / \mathrm{m}^{3}$ \\
\hline Droplet flow rate & $F_{d}$ & n.a. & $1.4 \cdot 10^{-5}$ & n.a. & $1.4 \cdot 10^{-5}$ & $\mathrm{~m}^{3} / \mathrm{s}$ \\
\hline Gas density & $\rho_{g}$ & 1.2 & 1.2 & 1.2 & 1.2 & $\mathrm{~kg} / \mathrm{m}^{3}$ \\
\hline Gas viscosity & $\mu_{g}$ & $1.8 \cdot 10^{-5}$ & $1.8 \cdot 10^{-5}$ & $1.8 \cdot 10^{-5}$ & $1.8 \cdot 10^{-5}$ & $\mathrm{~kg} /(\mathrm{m} \mathrm{s})$ \\
\hline $\begin{array}{l}\text { Background gas } \\
\text { velocity }\end{array}$ & $u_{b g}$ & 1.78 & 1.71 & 1.78 & 1.71 & $\mathrm{~m} / \mathrm{s}$ \\
\hline $\begin{array}{l}\text { Gas velocity in the } \\
\text { spout }\end{array}$ & $u_{j e t}$ & 1.78 & 22.9 & 1.78 & 22.9 & $\mathrm{~m} / \mathrm{s}$ \\
\hline $\begin{array}{l}\text { Number of cells in } \\
\text { the X-direction }\end{array}$ & $N X$ & 30 & 30 & n.a. & n.a. & - \\
\hline $\begin{array}{l}\text { Number of cells in } \\
\text { the Y-direction }\end{array}$ & $N Y$ & 30 & 30 & n.a. & n.a. & - \\
\hline $\begin{array}{l}\text { Number of cells in } \\
\text { the Z-direction }\end{array}$ & $N Z$ & 200 & 200 & n.a. & n.a. & - \\
\hline Time step particles & $\Delta t_{p}$ & $1.0 \cdot 10^{-4}$ & $1.0 \cdot 10^{-4}$ & n.a. & n.a. & $\mathrm{s}$ \\
\hline Time step droplets & $\Delta t_{d}$ & n.a. & $3.3 \cdot 10^{-5}$ & n.a. & n.a. & $\mathrm{s}$ \\
\hline Time step gas & $\Delta t_{g}$ & $1.0 \cdot 10^{-4}$ & $1.0 \cdot 10^{-4}$ & n.a. & n.a. & $\mathrm{s}$ \\
\hline
\end{tabular}


Figure 3 shows the measured and simulated porosities without (top) and with (bottom) the injection of a gas jet into the fluidized bed. In the figure it can be seen clearly, that the injection of the gas jet into the fluidized bed strongly effects the local porosities. The injection zone is characterized by high porosities which decrease at the borders of the injection zone. The injection region is followed by a region of nearly constant porosities in the fluidized bed region. At the wall of the fluidized bed a significant decrease of the porosity can be seen, which is due to the downward movement of the particles and the particle circulation in fluidized beds. With increasing distance from the bottom plate the porosity in the injection zone decreases steadily until it reaches nearly the same porosity as in the fluidized bed region. I.e. due to the particle entrainment into the jet and the particle acceleration the momentum of the atomization air is reduced and thus the influence of the atomization air on the fluidized bed reduces. At higher distances from the bottom plate the porosity in the centre of the fluidized bed increases because of the bubble coalescence and thus bubble growth in the upper region of bubbling fluidized beds.

For coating, granulation and agglomeration tasks this means, the deposition of the atomized liquid droplets on the fluidized particles is mainly influenced by the local particle volume concentrations in the injection region. The porosities themselves are influenced by the momentum of the atomization air.

\section{Numerical}
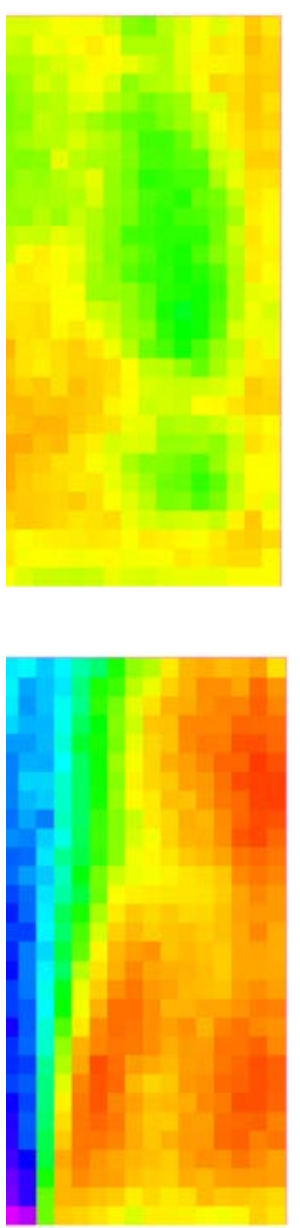

\section{Experimental}
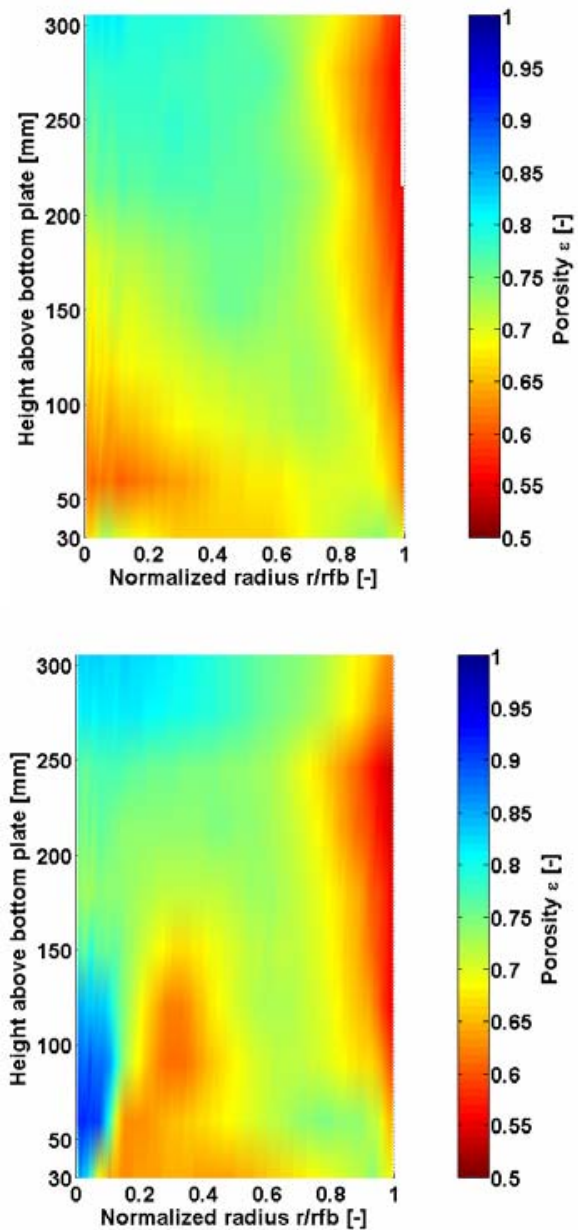

Figure 3 Measured and simulated time averaged porosities without (top) and with (bottom) injection of atomization air. Note that only the right half of the centre plane is shown. The results were obtained after $3 \mathrm{~s}$ time averaging. 


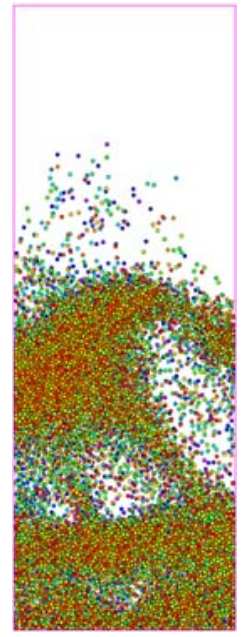

(a)

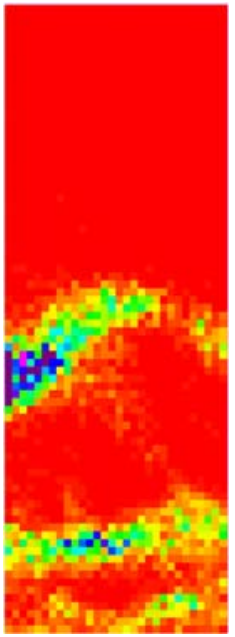

(b)

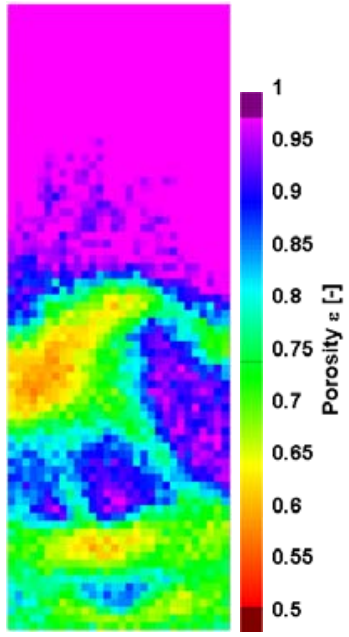

(c)

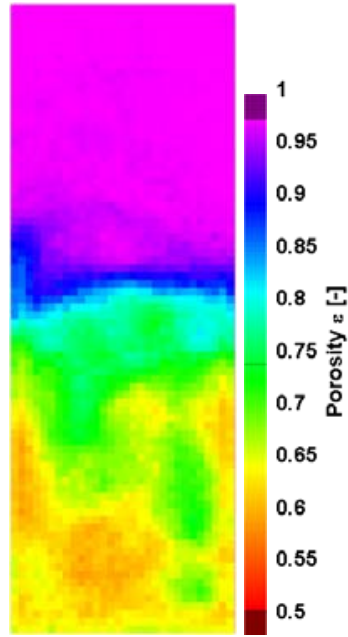

(d)

Figure 4 Calculated instantaneous particle positions (a), particle-particle collision rate with the colour blue indicating a collision rate of $4 \cdot 10^{9}$ collisions / $\left(\mathrm{m}^{3} \mathrm{~s}\right)(\mathrm{b})$, instantaneous porosity (c) and time averaged porosity (d) without injection of atomization air in a $0.01 \mathrm{~m}$ thick slab with a width of $0.3 \mathrm{~m}$ and a height of $1.0 \mathrm{~m}$ positioned at $y / D=0.5$.

When the measured and simulated porosities are compared, it is seen that the porosities qualitatively agree well. Better correspondence may be expected when (some of) the simplifying assumptions are overcome.

Figure 4 and 5 show additional results obtained from the discrete particle model simulations, i.e. instantaneous particle positions indicating the flow structures including bubble size and shape, particle-particle collision rates and porosity distributions. It is observed that the droplets (indicated in black in figure 5a) do not entirely penetrate the bed, which is good, since breakthrough is not desirable in the operation of spout fluid beds. Furthermore it can be seen that the area of influence of the spout is rather limited. Depending on the time scales of moisture absorption and circulation of the particles in the bed, changes to the geometry and/or the operating conditions may be considered. These and other relevant aspects will be studied in more detail in future work.

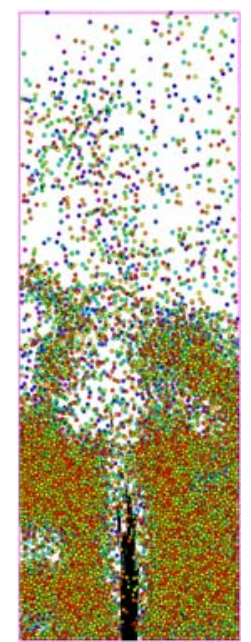

(a)

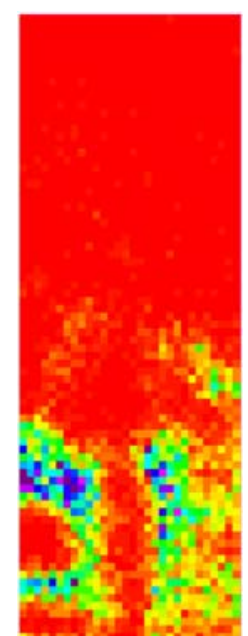

(b)

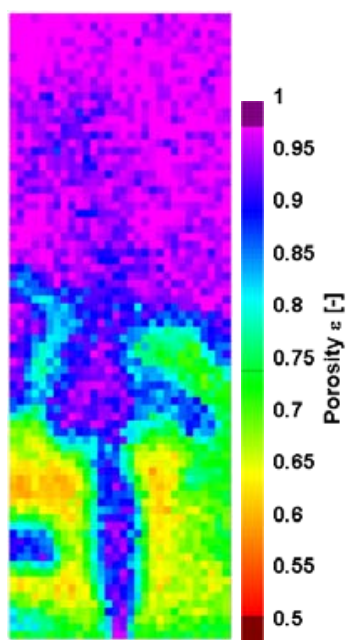

(c)

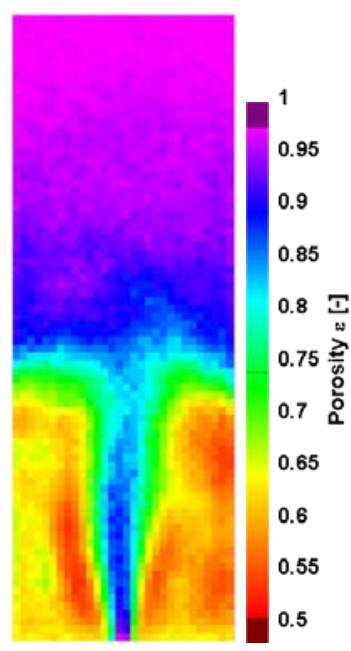

(d)

Figure 5 Calculated instantaneous particle positions (a), particle-particle collision rate with the colour blue indicating a collision rate of $4 \cdot 10^{9}$ collisions / $\left(\mathrm{m}^{3} \mathrm{~s}\right)(\mathrm{b})$, instantaneous porosity (c) and time averaged porosity (d) without injection of atomization air in a $0.01 \mathrm{~m}$ thick slab with a width of $0.3 \mathrm{~m}$ and a height of $1.0 \mathrm{~m}$ positioned at $y / D=0.5$. 


\section{CONCLUSIONS}

In this work a first attempt was made to compare fibre optical measurement results with results from numerical simulations with a discrete element model. It was found that both techniques are valuable and complimentary tools to study the fluidization and granulation behavior in spout fluid beds. They can provide useful information on the size of the growth zone, the nature of the particle droplet contact, etc.

Further work is necessary to ensure that the assumptions used in the numerical simulations are viable. Subsequently a more detailed study will be made to get a better understanding of the details of the fluid dynamics and their influence on the granulation process.

\section{REFERENCES}

[1] Merry, J.M.D., Fluid and particle entrainment into vertical jets in fluidized beds, AIChE Journal 21(1975) 3, pp. 507-510.

[2] Merry, J.M.D., Penetration of vertical jets into fluidized beds, AIChE Journal 22 (1976) 2, pp. 315-323.

[3] Massimilla, L., De Michelle, G., Eila, A., The interaction between jets and fluidized beds, Ing. Chim. Ital. 12 (1976) 11-12, pp. 155-162.

[4] Massimilla, L., Donado, S., Mechanism of momentum and heat transfer between gas jets and fluidized beds, Fluid. Poc. Eng. Found., 2 (1978)

[5] Massimilla, L., Donado, S., Maresca, A., Gas injection in shallow beds of fluidized coarse particles, Ing. Chim. Ital. 16 (1980) 1-2, pp. 1-10.

[6] Massimilla, L., Donsi, G., Miglaccio, N., The dispersion of gas jets in two dimensional fluidized beds of coarse particles, AIChE Journal (1981), pp. 17-27.

[7] Massimilla, L., Filla, M., Vacarro, S., Gas jets in fluidized beds: The influence of particle size, shape and density on gas and solids entrainment, Int. J. of Multiphase Flow 9 (1983), pp. 259-267.

[8] Massimilla, L., Filla, M., Vacarro, S., Gas jets in fluidized beds and spouts, Comparision of experimental behaviour and models, Can. J. Chem. Eng. 61 (1983), pp. 370-376.

[9] Massimilla, L., Filla, M., Analysis of the variables controlling gas jet penetration in fluidized beds, Ind. Eng. Chem. Fundam. 23 (1984) 1, pp. 131-132.

[10] Yang, W.-C., Keairns, D. L., Estimating the jet penetration depth of multiple vertical grid jets, Ind. Eng. Chem. Fundam. 18 (1979) 4, pp. 317-320.

[11] Yang, W.-C., Keairns, D. L., Momentum dissipation and gas entrainment into a gas jet in a fluidized bed, AIChE Journal 77 (1981) 205, pp. 28-36.

[12] Hong, R., Hongzhong ,L., Maoyu, C., Jiyu, Z., Numerical simulation and verification of a gas-solid jet fluidized bed, Powder Technology 87 (1996), pp. 73-81.

[13] Becher, R.D., Schlünder, E.-U., Fluidized bed granulation: gas flow, particle motion, and moisture distribution, Chem. Eng. Proc. 36 (1997a), pp. 261-269.

[14] Becher, R.D., Untersuchung der Agglomeration von Partikeln bei der Wirbelschicht-Sprühgranulation, Doctoral thesis TU Karlsruhe 1997b,VDI-Fortschrittsbericht Reihe 3 Nr. 500.

[15] Heinrich, S., Mörl, L., Fluidized bed spray granulation - A new modal for the description of particle wetting and of temperature and concentration distribution, Chem. Eng. Proc. 38 (1999), pp. 635-663.

[16] Heinrich, S., Blumschein, J., Henneberg, M., Ihlow, M., Peglow, M., Mörl, L., Study of dynamic multidimensional temperature and concentration distributions in liquid-sprayed fluidized beds, Chem. Eng. Sci. 58 (2003), pp. 5135-5160.

[17] Patil, D.J., van Sint Annaland, M., Kuipers, J.A.M., Critical comparison of hydrodynamic models for gasfluidized beds - Part I: bubbling gas-solid fluidized beds operated with a jet, Chem. Eng. Sci. 60 (2005), pp. 57-72.

[18] Link, J.M., Cuypers, L.A., Deen, N.G., Kuipers, J.A.M., Flow regimes in a spout-fluid bed: a combined experimental and simulation study, Chem. Eng. Sci. 60 (2005), pp. 57-72.

[19] Hartge, E.-U., Rensner, D., Werther, J., Faseroptisches Messsystem zur Erfassung lokaler Feststoffkonzentrationen und -geschwindigkeiten in höher konzentrierten Gas-/ Feststoffströmungen, Chem.-Ing.-Tech. (1989) MS 1781/89.

[20] Hoomans, B.P.B., Kuipers, J.A.M., Briels, W.J. and Van Swaaij, W.P.M., Discrete particle simulation of bubble and slug formation in a two-dimensional gas-fluidised bed: A hard-sphere approach, Chem. Eng. Sci. 51 (1996) 99-118.

[21] Koch, D.L. and Hill, R.J., Inertial effects in suspension and porous-media flows, Annu. Rev. Fluid Mech. 33 (2001) 619-647.

[22] Kharaz, A.H., Gorham, D.A., Salman, A.D., An experimental study of the elastic rebound of spheres, Powder Technology 120, 2001, pp. 281-291.

[23] Goldschmidt, M.J.V., Kuipers, J.A.M. and Van Swaaij, W.P.M., Hydrodynamic modeling of dense gasfluidised beds using the Kinetic Theory of Granular Flow: Effect of coefficient of restitution on bed dynamics, Chem. Eng. Sci. 56 (2001) 571-578. 